\title{
Review
}

\section{Hysteroscopy Versus Laparoscopy in the Management of Isthmocele: A Review of the Literature}

\author{
Mohammad Jaffal, MD'; Marco Mouanness, MD'; Anastasia Salame, MD²; Maelle Saliba, MD'; Karine Azar, BS³; \\ Georges Rameh, MD ${ }^{*}$ \\ 'Department of Obstetrics and Gynecology, American University of Beirut Medical Center (AUBMC), Beirut, Lebanon \\ ${ }^{2}$ Fakih Fertility Center, Al Ain City, Abu Dhabi, United Arab Emirates \\ ${ }^{3}$ School of Medicine and Medical Sciences, Holy Spirit University of Kaslik, Jbeil, Lebanon

\section{*Corresponding authors} \\ Georges Rameh, MD \\ Department of Obstetrics and Gynecology,American University of Beirut Medical Center (AUBMC), Beirut, Lebanon;Tel. 009613000 636; \\ E-mail: grl3@aub.edu.lb; george_rameh@hotmail.com
}

\section{Marco Mouanness, MD}

Department of Obstetrics and Gynecology,American University of Beirut Medical Center (AUBMC), Beirut, Lebanon;Tel. 0096 I 70 I60 362; E-mail: mm218@aub.edu.lb; marco.mouannes@yahoo.com

\section{Article information}

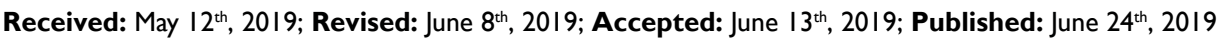

\section{Cite this article}

Jaffal M, Mouanness M, Salame A, Saliba M,Azar K, Rameh G. Hysteroscopy versus laparoscopy in the management of isthmocele:A review of the literature. Women Health Open J. 20I9; 5(I): 6-II. doi: I0.17I40/WHOJ-5-I30

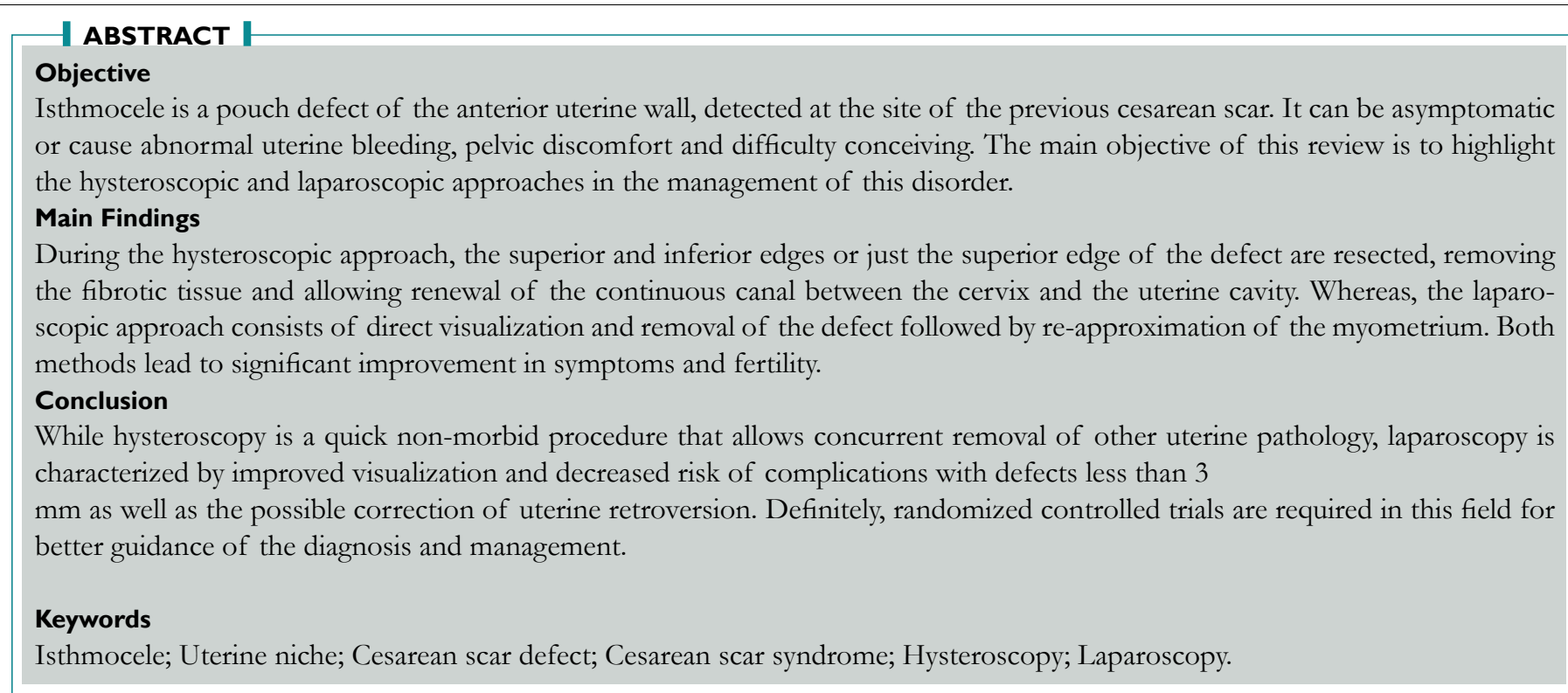

\section{INTRODUCTION}

C esarean section, the most common surgical procedure performed worldwide, has been linked to several obstetrical and gynecological complications.

Stemming from an incongruent post-operative healing of the lower uterine segment, multiple consequences may complicate future gynecological or obstetrical outcomes. They include but are not limited to placenta accreta, scar dehiscence, cesarean-scar ecto- pic pregnancy, and isthmocele. ${ }^{1}$

Isthmocele, also known as uterine niche, cesarean scar defect or cesarean scar syndrome, is a pouch defect of the anterior uterine wall, detected at the site of the previous cesarean scar. Despite the fact that many women with this defect may be asymptomatic, others might present with a wide range of complaints, including intermittent spotting or bleeding, pelvic discomfort and difficulty conceiving., ${ }^{2,3}$ 
The following review will tackle the main modalities of treatment, comparing the hysteroscopic and laparoscopic approaches, in the management of an increasingly emerging disorder.

\section{Risk Factors and Prevalence}

The most important risk factor for isthmocele formation is the presence of a lower uterine scar. Therefore, cesarean section deliveries have been directly linked to isthmocele formation, at a rate as high as $100 \%$ after the third cesarean section. ${ }^{4}$

Other factors that hinder proper healing of the uterine scar, such as preterm premature rupture of membranes, have been implicated in the formation of isthmocele by creating a proliferative environment for infection hence weakening the recovery and closure of the uterine scar. ${ }^{5}$

Furthermore, factors related to the operation itself have been linked to the development of uterine niches including the length of the operation, the operative technique and the indication for cesarean. It is important to mention for example that a cesarean section performed at advanced cervical dilation and lower fetal station has been associated with a higher rate of niches. ${ }^{6}$

The prevalence of this diagnosis varies significantly between different studies, reportedly ranging from $19.4 \%$ and $88 \%$ depending on the population studied and the country of origin.

The evidence available on the management options are mainly based on case reports and series. In fact, the lack of properly designed studies, including randomized controlled trials, compose a major barrier for a universally accepted diagnostic definition and gold standard therapeutic guidelines.

\section{Diagnosis}

The diagnosis of isthmocele is usually clinical, in combination with transvaginal ultrasound, magnetic resonance imaging (MRI) or hysteroscopy.

In addition to the traditionally used $2 \mathrm{D}$ ultrasound, the 3D ultrasound with or without sonohysterogram constitutes a promising diagnostic tool.

Imaging is ideally done at the end of the menstrual cycle to ensure a thin endometrial lining thus enabling the measurement of the niche thickness and directing the clinician towards the ideal management approach. ${ }^{9}$

In case of diagnostic uncertainty, an office hysteroscopy, with or without cervical dilation and anesthesia, can be performed in order to directly visualize the defect and proceed with the best treatment plan.

\section{Management}

The incidental finding of an isthmocele on ultrasound should not prompt the physician to undergo corrective measures. In fact, asymptomatic isthmocele is a commonly encountered condition that doesn't require any additional treatment.

Bothersome symptomatic isthmocele (whether gynecological, obstetrical or related to infertility) should be better evaluated for treatment. The treatment of choice is usually surgical since medical treatment does not allow the correction of the defect and will not resolve the problem at hand.

Various operative techniques have been described in the literature to correct this defect, with different approach considerations, including hysteroscopy, laparoscopy/robotics, or vaginal approach.?

\section{Hysteroscopy}

The hysteroscopic approach is a minimally invasive procedure that has the added benefit of distending the uterine cavity therefore allowing for direct visualization of the isthmocele.

The surgical correction of the isthmocele by hysteroscopy is done by resection of the superior and inferior edges or just the superior edge of the defect with a resectoscopic loop, using pure cutting current, until reaching the muscular layer (Figure 1).

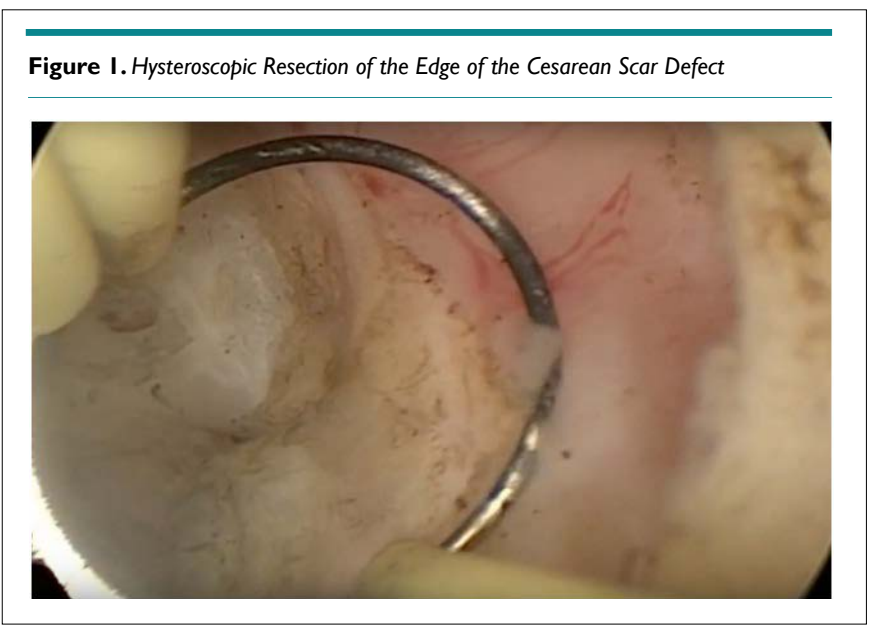

Histologic analysis of the scar edges usually show chronic inflammatory infiltration, fibrosis and necrotic tissues. ${ }^{2}$

Thus, the aim of this procedure is mainly removing this fibrotic tissue, which will be replaced by a non-inflamed new epithelial layer preventing adhesion formation and allowing renewal of the continuous canal between the cervix and the uterine cavity. ${ }^{2,10}$

The first study to portray this technique was published in 2005 by Fabres et al describing the hysteroscopic correction of the cesarean scar defects, diagnosed by transvaginal ultrasound, in twenty-four symptomatic women. On follow-up, these women reported significantly improved symptoms as well as fertility. ${ }^{11}$ 
This procedure was shown to be effective in treating abnormal uterine bleeding caused by cesarean scar defects. ${ }^{12}$

Furthermore, one of the added benefits of this procedures is that it does not reduce the uterine wall thickness. The technique itself is based on removal of the fibrotic and scarred tissue without the adjacent myometrium thus preventing any thinning of normal myometrial tissue. This was documented by biopsies performed after hysteroscopic repair. ${ }^{2}$

Another study evaluated the myometrial thickness before and after the procedure using MRI. It showed that the mean thickness increased significantly from $2.1 \mathrm{~mm}$ before the resection to $4.2 \mathrm{~mm}$ after the surgery. ${ }^{13}$ And since residual myometrial thickness of less than $2 \mathrm{~mm}$ is associated with a significant increase in the risk of uterine rupture, this technique should theoretically be associated with decreased possibility of a uterine rupture during subsequent trials of labor. ${ }^{14,15}$

Similarly, the duration of menses after hysteroscopic treatment of isthmocele was shown to be significantly shorter from a mean of 12 days to 7.8 days along with a significant increase in patient satisfaction. ${ }^{16}$

Another prospective study evaluated 41 patients with secondary infertility, abnormal uterine bleeding after their menses and suprapubic pelvic pain, diagnosed with a cesarean scar defect. After hysteroscopic treatment, all patients reported resolution of their symptoms and became pregnant spontaneously between 1 and 2 years after surgery. No complications were noted. ${ }^{2}$

When comparing the effectiveness of hysteroscopic resection and hormonal treatment (combined estrogen and progesterone) in improving the symptoms of abnormal post-menstrual bleeding and suprapubic pain, both treatments showed improved symptoms; but women who underwent surgical resection had a higher degree of satisfaction, less pelvic pain and shorter menses. Although, evaluation of persistent improvement in symptoms after stopping the hormonal treatment was not done, hysteroscopic resection will probably have a more durable effect. ${ }^{17,18}$

Preoperative evaluation, mainly via transvaginal ultrasound, is fundamental before hysteroscopic repair to check the uterine wall thickness, the residual myometrial layer thickness and possible adhesions.

It is significant to mention that the mean time required for hysteroscopic treatment was 8 minutes, which makes it a non-morbid and quick procedure, allowing the removal of other uterine pathology such as polyps at the same time.'

In conclusion, randomized controlled trials are required in this field, to study the prevalence of infertility in women with cesarean scar defects, the safety of conception after hysteroscopic resection and its possible role in the management of secondary infertility. ${ }^{10}$

\section{Laparoscopy}

Laparoscopic surgery has been widely used in the management of gynecological disorders during the past decades.

The first laparoscopic cesarean scar defect repair was described by Jacobson et al. Since then, laparoscopy has played an important role in the management of isthmocele, both on a diagnostic and therapeutic level. ${ }^{19}$

Laparoscopy is believed to be optimal for scar defect patients seeking fertility due to improved visualization and the ability to reapproximate the myometrium using single or multiple layer closure, in addition to the use of laparoscopy at this stage as a diagnostic and therapeutic modality for other pathological findings commonly encountered in patients with niches, such as endometriosis. $^{20}$

Laparoscopy decreases the risk of bladder injury and uterine perforation with defects less than $3 \mathrm{~mm} .^{21}$

Different laparoscopic approaches have been described in the literature.

One procedure described included careful bladder mobilization from its adhesions to the site of the previous cesarean scar, thus freeing the vesicovaginal space. The cesarean scar is then removed with cold scissors, avoiding the use of polarizing energy to reduce the risk of tissue necrosis (Figure 2). The myometrial repair is performed after this with the use of a single-layer of interrupted polyglactin sutures. $^{22}$

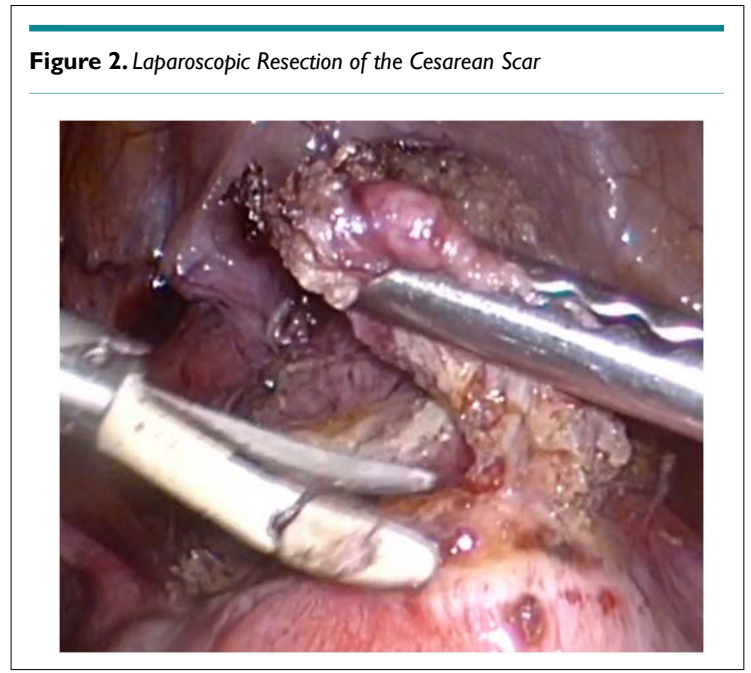

Another technique, similar to the one previously illustrated, has been described. This technique differs by the surgical repair of the myometrial repair by two-layers instead of one only. Interrupted polyglactin sutures are used for the first and the second layer. The peritoneum is then closed using Monocryl sutures. ${ }^{17}$

A third technique included a multi-layer closure: the first layer is sutured with interrupted mattress sutures with monofila- 
ment non-barbed polydioxanone suture; the second layer is placed to imbricate over the initial closure with the same suture material in a running or mattress style; and the last layer is closed with 3-0 barbed suture in a running 'baseball' style. ${ }^{23}$

Hysteroscopic simultaneous assistance during laparoscopic isthmocele repair can be of great help in identifying the edges of the defect, especially in large cavities (Figure 3). ${ }^{24,25}$

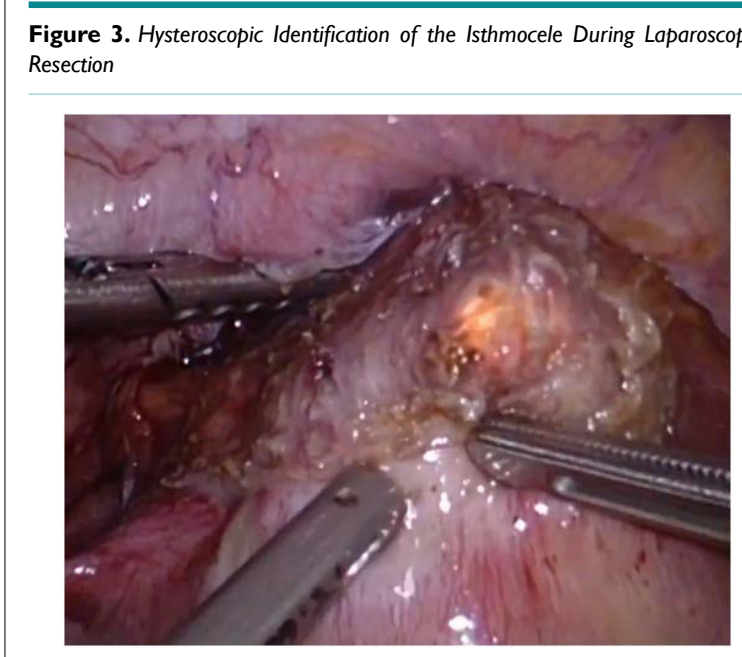

Several studies showed that laparoscopic repair of cesarean scar defects led to the improvement of uterine bleeding disorders in $86 \%$ of cases and a pregnancy rate of $55 \% .^{26,27}$

Marrota et al reported 13 cases of laparoscopic repair in women with residual myometrial thickness less than $3 \mathrm{~mm}$ who planned to conceive. All cases had complete resolution of the symptoms, with 3 uncomplicated pregnancies and deliveries. ${ }^{28}$

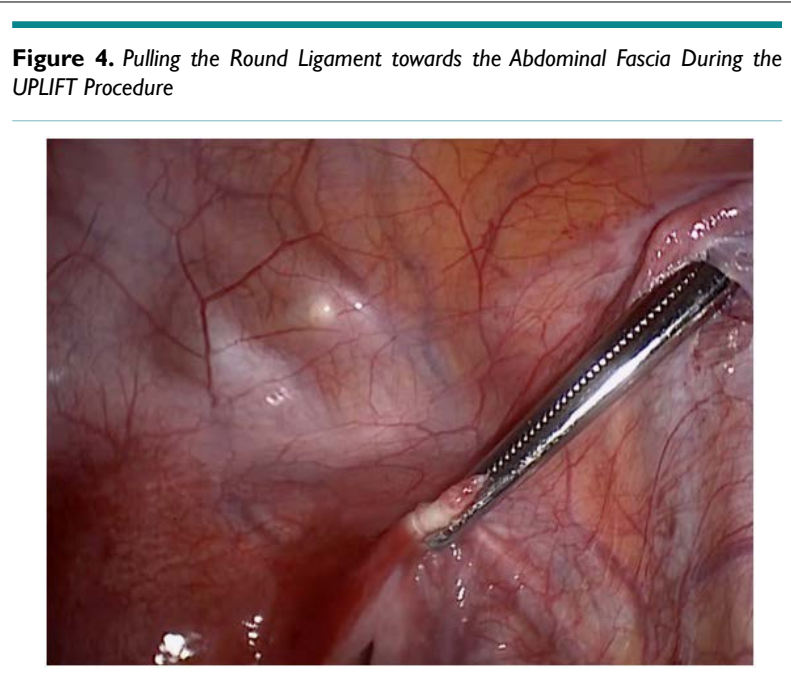

Since retroverted uteri have been linked to pelvic pain, dysmenorrhea, dyspareunia and probably to decreased healing of a cesarean scar and increased risk of a uterine niche. Choosing the laparoscopic approach to isthmocele repair adds the advantage of correcting the retroversion. This was described by Vervoort et al as the "UPLIFT" procedure (uterine positioning by ligament investment fixation and truncation). Diverse approaches to the correction of the retroversion have been described, all based on the shortening of the round ligament. This shortening can be achieved by fixation of the round ligament anteriorly to the abdominal fascia or by a purse-string suture along the round ligament (Figures 4 and 5$) \cdot{ }^{20}$

\section{Figure 5. Shortening of the round Ligament with Intra-Corporeal Suture During the Uplift Procedure}

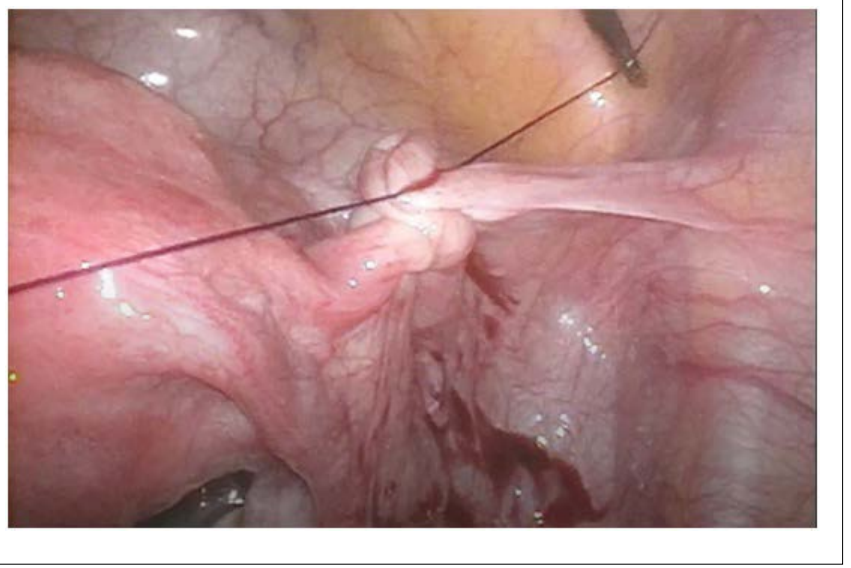

\section{DISCUSSION}

Each technique of isthmocele correction offers its own benefits and disadvantages. The decision to proceed with one technique or the other should be made on a case-by-case basis and should be guided by the operator's preference and experience. It is without a doubt that the latter plays a major role in the proper correction of the isthmocele.

Both hysteroscopy and laparoscopy were shown to significantly improve abnormal uterine bleeding and difficulty conceiving from isthmocele. ${ }^{29}$

Hysteroscopy is a quick minimally invasive procedure that allows direct visualization of the isthmocele, resection of the edges of the scar defect as well as concurrent removal of other uterine pathology..$^{30}$ The fibrotic tissue removed will be replaced by a noninflamed epithelial layer allowing renewal of the continuous canal between the cervix and the uterine cavity. ${ }^{31,32}$

Laparoscopy is optimal for patients seeking fertility due to improved visualization and direct reapproximation of the myometrium. It is also characterized by a lower risk of bladder injury and uterine perforation. Furthermore, laparoscopy can diagnose and treat other pathologic findings such as endometriosis, in addition to the possibility of uterine retroversion correction.

The technique combining hysteroscopy and laparoscopy offers the added value of direct visualization of the defect by transillumination, thus ensuring a better resection of the isthmocele. However, to date, no studies have been done comparing this 
technique to hysteroscopy or laparoscopy alone.

Also, no randomized controlled trials have been done comparing the hysteroscopic approach to the laparoscopic one. It is of certainty that such studies will offer a better guidance to clinicians in the management of isthmocele.

It would be imperative to study the reason why some patients develop a cesarean scar defect and others don't. Some authors have incriminated uterine closure techniques during cesarean section as a determinant factor in the formation of the defect, while others have speculated an innate defective regenerative system as the main cause. ${ }^{33}$

With the recent increase in the rate of cesarean section, worldwide increase in post-operative complications has been noticed. ${ }^{33}$ Isthmocele will be more frequently encountered within the next decades, with its various clinical presentations and implications. ${ }^{34}$ Hence, there is an increasingly emergent need for more evaluation of operative techniques in uterine closure during cesarean section to prevent this complication. ${ }^{3.5}$

The diagnostic dilemma of cesarean scar defect remains an issue as well. So far, diagnosis is mainly clinical with no strict imaging criteria. Evidently, better guidance of the clinicians would be achieved by implementing more detailed diagnostic criteria based on randomized controlled trials on clinical presentations and imaging findings.

\section{CONCLUSION}

With the increase in the incidence of cesarean sections worldwide, gynecologists will be faced with the emergence of a new disorder known as the isthmocele. Both hysteroscopy and laparoscopy seem to be good management options for the treatment of abnormal uterine bleeding, pelvic pain and subfertility secondary to this condition. Hysteroscopy is a quick non-morbid procedure that allows concurrent removal of other uterine pathology, a fast recovery while being cost-effective. Laparoscopy is characterized by improved visualization of the defect, decreased risk of complications with defects less than $3 \mathrm{~mm}$ as well as the possible correction of uterine retroversion. Due to the sparse published evidence in this field, randomized controlled trials including larger groups of patients are required for better guidance of the diagnosis and management.

\section{CONFLICTS OF INTEREST |}

The authors declare that they have no conflicts of interest.

\section{REFERENCES}

1. Tower AM, Frishman GN. Cesarean scar defects: An underrecognized cause of abnormal uterine bleeding and other gynecologic complications. J Minim Invasive Gynecol. 2013; 20(5): 562-572. doi: 10.1016/j.jmig.2013.03.008
2. Gubbini G, Centini G, Nascetti D, et al. Surgical hysteroscopic treatment of cesarean-induced isthmocele in restoring fertility: Prospective study. J Minim Invasive Gynecol. 2011; 18(2): 234-237. doi: 10.1016/j.jmig.2010.10.011

3. Borges LM, Scapinelli A, de Baptista Depes D, Lippi UG, Coelho Lopes RG. Findings in patients with postmenstrual spotting with prior cesarean section. J Minim Invasive Gynecol. 2010; 17(3): 361-364. doi: 10.1016/j.jmig.2010.02.007

4. Osser OV, Jokubkiene L, Valentin L. High prevalence of defects in cesarean section scars at transvaginal ultrasound examination. Ultrasound Obstet Gynecol. 2009; 34(1): 90-97. doi: 10.1002/uog.6395

5. Hayakawa H, Itakura A, Mitsui T, et al. Methods for myometrium closure and other factors impacting effects on cesarean section scars of the uterine segment detected by the ultrasonography. Acta Obstet Gynecol Scand. 2006; 85(4): 429-434. doi: 10.1080/00016340500430436

6. Park IY, Kim MR, Lee HN, Gen Y, Kim MJ. Risk factors for Korean women to develop an isthmocele after a cesarean section. BMC Pregnancy Childbirth. 2018; 18(1): 1-10. doi: 10.1186/s12884018-1821-2

7. Api M, Boza A, Gorgen H, Api O. Should cesarean scar defect be treated laparoscopically? A case report and review of the literature. J Minim Invasive Gynecol. 2015; 22(7): 1145-1152. doi: 10.1016/j.jmig.2015.06.013

8. Ludwin A, Martins WP, Ludwin I. Evaluation of uterine niche by three-dimensional sonohysterography and volumetric quantification: techniques and scoring classification system. Ultrasound $\mathrm{Ob}$ stet Gynecol. 2019; 53(1): 139-143. doi: 10.1002/uog.19181

9. Nezhat C, Falik R, Li A. Surgical management of niche, isthmocele, uteroperitoneal fistula, or cesarean scar defect: A critical rebirth in the medical literature. Fertil Steril. 2017; 107(1): 69-71. doi: 10.1016/j.fertnstert.2016.10.017

10. Raimondo G, Grifone G, Raimondo D, Seracchioli R, Scambia G, Masciullo V. Hysteroscopic treatment of symptomatic cesarean-induced isthmocele: A prospective study. J Minim Invasive Gynecol. 2015; 22(2): 297-301. doi: 10.1016/j.jmig.2014.09.011

11. Fabres C, Arriagada P, Fernández C, MacKenna A, Zegers F, Fernández E. Surgical treatment and follow-up of women with intermenstrual bleeding due to cesarean section scar defect. J Minim Invasive Gynecol. 2005; 12(1): 25-28. doi: 10.1016/j.jmig.2004.12.023

12. Sanders AP, Murji A. Hysteroscopic repair of cesarean scar isthmocele. Fertil Steril. 2018; 110(3): 555-556. doi: 10.1016/j.fertnstert.2018.05.032

13. Tsuji S, Kimura F, Yamanaka A, et al. Impact of hysteroscopic surgery for isthmocele associated with cesarean scar syndrome. $J$ Obstet Gynaecol Res. 2018; 44(1): 43-48. doi: 10.1111/jog.13464 
14. Jastrow N, Demers S, Chaillet N, et al. Lower uterine segment thickness to prevent uterine rupture and adverse perinatal outcomes: A multicenter prospective study. Am J Obstet Gynecol. 2016; 215(5): 604.e1-604.e6. doi: 10.1016/j.ajog.2016.06.018

15. Landon MB, Hauth JC, Leveno KJ, et al. Maternal and perinatal outcomes associated with a trial of labor after prior cesarean delivery. N Engl J Med. 2004; 351(25): 2581-2589. doi: 10.1056/ NEJMoa040405

16. Muzii L, Domenici L, Lecce F, et al. Clinical outcomes after resectoscopic treatment of cesarean-induced isthmocele: A prospective case-control study. Eur Rev Med Pharmacol Sci. 2017; 21(15): 3341-3346.

17. Florio P, Gubbini G, Marra E, et al. A retrospective case-control study comparing hysteroscopic resection versus hormonal modulation in treating menstrual disorders due to isthmocele. Gynecol Endocrinol. 2011; 27(6): 434-438. doi: 10.3109/09513590.2010.495431

18. Tahara M, Shimizu T, Shimoura H. Preliminary report of treatment with oral contraceptive pills for intermenstrual vaginal bleeding secondary to a cesarean section scar. Fertil Steril. 2006; 86(2): 477-479. doi: 10.1016/j.fertnstert.2006.01.020

19. Jacobson MT, Nezhat CR, Velasco A, Charles R. Laparoscopic repair of a uteroperitoneal fistula. Fertil Steril. 2002; 74(3): S200. doi: 10.1016/s0015-0282(00)01308-x

20. Donnez O, Donnez J, Orellana R, Dolmans MM. Gynecological and obstetrical outcomes after laparoscopic repair of a cesarean scar defect in a series of 38 women. Fertil Steril. 2017; 107(1): 289 296.e2. doi: 10.1016/j.fertnstert.2016.09.033

21. Bujold E, Jastrow N, Simoneau J, Brunet S, Gauthier RJ. Prediction of complete uterine rupture by sonographic evaluation of the lower uterine segment. Am J Obstet Gynecol. 2009; 201(3): 320. e1-320.e6. doi: 10.1016/j.ajog.2009.06.014

22. Aimi G, Buggio L, Berlanda N, Vercellini P. Laparoscopic repair of a symptomatic post-cesarean section isthmocele: A video case report. Fertil Steril. 2017; 107(6): e17-e18. doi: 10.1016/j.fertnstert.2017.04.004

23. Sipahi S, Sasaki K, Miller CE. The minimally invasive approach to the symptomatic isthmocele-what does the literature say? A step-by-step primer on laparoscopic isthmocele-excision and repair. Curr Opin Obstet Gynecol. 2017; 29(4): 257-265. doi: 10.1097/ GCO.0000000000000380

24. Suarez Salvador E, Haladjian MC, Bradbury M, et al. Laparoscopic isthmocele repair with hysteroscopic assistance. J Minim In vasive Gynecol. 2018; 25(4): 576-577. doi: 10.1016/j.jmig.2017.10.005
25. Donnez O, Jadoul P, Squifflet J, Donnez J. Laparoscopic repair of wide and deep uterine scar dehiscence after cesarean section. Fertil Steril. 2008; 89(4): 974-980. doi: 10.1016/j.fertnstert.2007.04.024

26. Zhang Y. A comparative study of transvaginal repair and laparoscopic repair in the management of patients with previous cesarean scar defect. J Minim Invasive Gynecol. 2016; 23(4): 535-541. doi: 10.1016/j.jmig.2016.01.007

27. Tanimura S, Funamoto H, Hosono T, et al. New diagnostic criteria and operative strategy for cesarean scar syndrome: Endoscopic repair for secondary infertility caused by cesarean scar defect. $J$ Obstet Gynaecol Res. 2015; 41(9): 1363-1369. doi: 10.1111/jog.12738

28. Marotta ML, Donnez J, Squifflet J, Jadoul P, Darii N, Donnez O. Laparoscopic repair of post-cesarean section uterine scar defectsdiagnosed in nonpregnant women. J Minim Invasive Gynecol. 2013; 20(3): 386-391. doi: 10.1016/j.jmig.2012.12.006

29. Allornuvor GFN, Xue M, Zhu X, Xu D. The definition, aetiology, presentation, diagnosis and management of previous caesarean scar defects. J Obstet Gynaecol (Lahore). 2013; 33(8): 759-763. doi: 10.3109/01443615.2013.816663

30. Xu D, He Y, Liu H, Wan Y, Xue M. Hysteroscopic treatment of women with previous cesarean scar defect. Nan Fang Yi Ke Da Xue Хиe Bao. 2010; 30(2): 394-396.

31. Fernandez E, Fernandez C, Fabres C, Alam V V. Hysteroscopic correction of cesarean section scars in women with abnormal uterine bleeding. J Am Assoc Gynecol Laparosc. 1996; 3(4, Supplement): S13. doi: 10.1016/S1074-3804(96)80170-8

32. Wang CJ, Huang HJ, Chao A, Lin YP, Pan YJ, Horng SG. Challenges in the transvaginal management of abnormal uterine bleeding secondary to cesarean section scar defect. EurJ Obstet Gynecol Reprod Biol. 2011; 154(2): 218-222. doi: 10.1016/j.ejogrb.2010.10.016

33. Betrán AP, Merialdi M, Lauer JA, et al. Rates of caesarean section: analysis of global, regional and national estimates. Paediatr Perinat Epidemiol. 2007; 21(2): 98-113. doi: 10.1111/j.13653016.2007.00786.x

34. Wang CB, Chiu WWC, Lee CY, Sun YL, Lin YH, Tseng CJ. Cesarean scar defect: Correlation between cesarean section number, defect size, clinical symptoms and uterine position. Ultrasound Obstet Gynecol. 2009; 34(1): 85-89. doi: 10.1002/uog.6405

35. Yazicioglu F, Gökdogan A, Kelekci S, Aygün M, Savan K. Incomplete healing of the uterine incision after caesarean section: Is it preventable? Eur J Obstet Gynecol Reprod Biol. 2006; 124(1): 32-36. doi: 10.1016/j.ejogrb.2005.03.023 